\title{
SENSOR BASED SMART IRRIGATION SYSTEM WITH MONITORING AND CONTROLLING USING INTERNET OF THINGS
}

\author{
Nazmul Hassan, Sheikh Hasib Cheragee, Sakil Ahammed and \\ Abu Zafor Md. Touhidul Islam \\ Department of Electrical and Electronic Engineering, University of Rajshahi, \\ Rajshahi-6205, Bangladesh
}

\begin{abstract}
This paper presents the development of a sensor based smart irrigation system with the capabilities of remote monitoring and controlling of water usage in the agriculture field using Internet of Things (IoT). With the employment of IoT in irrigation system, all agricultural information can be viewed and controlled at the user's fingertips. The system consists of a microcontroller (Node MCU), sensors (soil moisture, DHT11), and irrigation of a water pump with a decision-making system. Sensors are linked to a Wi-Fi module (Node $M C U)$ and are interdependent to provide increased sensitivity to the irrigation system. The data obtained will be uploaded to the cloud (ThingSpeak) and presented in the form of graphs accessible via the website. A web page is used to control the water pump for irrigation purposes. This paper is managed to meet all of its aims to help farmers in terms of time, project cost, labor, water consumption, power consumption, and reliability by implementing the IoT-based smart irrigation system.
\end{abstract}

\section{KEYWORDS}

Internet of Things (IoT), smart agriculture, advanced agriculture practices, urban farming, automation, agriculture robots

\section{INTRODUCTION}

Agriculture is the main source of income for the majority of Bangladesh's population and a significant contributor to the country's economy. However, technological involvement and usability for the agro sector in Bangladesh must be grown and cultivated. Cloud control technology is rapidly evolving, infiltrating every industry and dramatically improving the sector's condition[1]. In recent years, cloud and IoT technology have entered agriculture, and by utilizing these two technologies, farmers are increasing production while decreasing costs. Precision agriculture is another name for smart agriculture. A variety of sensing technologies are often used in precision agriculture to provide data that helps growers to monitor and optimize crops as well as to adapt to changing environmental factors, such as location sensors, optical sensors, electrochemical sensors, Mechanical Sensors, Dielectric Soil Moisture Sensors, Airflow Sensors, Agricultural Weather Stations, humidity sensors, proximity sensors, and pH sensors. [2]. Agriculture is one of the fields that requires a large amount of water. Water waste is a major issue in agriculture. Every time there is an overabundance of water applied to the fields. In contrast to traditional irrigation methods, a smart irrigation system regulates supplied water based on the needs of the fields and crops. Users of smart irrigation systems can track their irrigation status, start and stop the process with a single button press, and receive updates on moisture levels, weather updates, and crop status. To provide 
these several objectives, a smart irrigation system should be set up with six main features that are shown in Fig. 1.

We will create a system that will allow a farmer to know the status of his field irrigation from the comfort of his own home or from anywhere in the world. The primary goal of this paper is to create an IoT-based smart irrigation system that will reduce water consumption while increasing productivity. This system is best suited for areas where water is scarce and must be used sparingly.

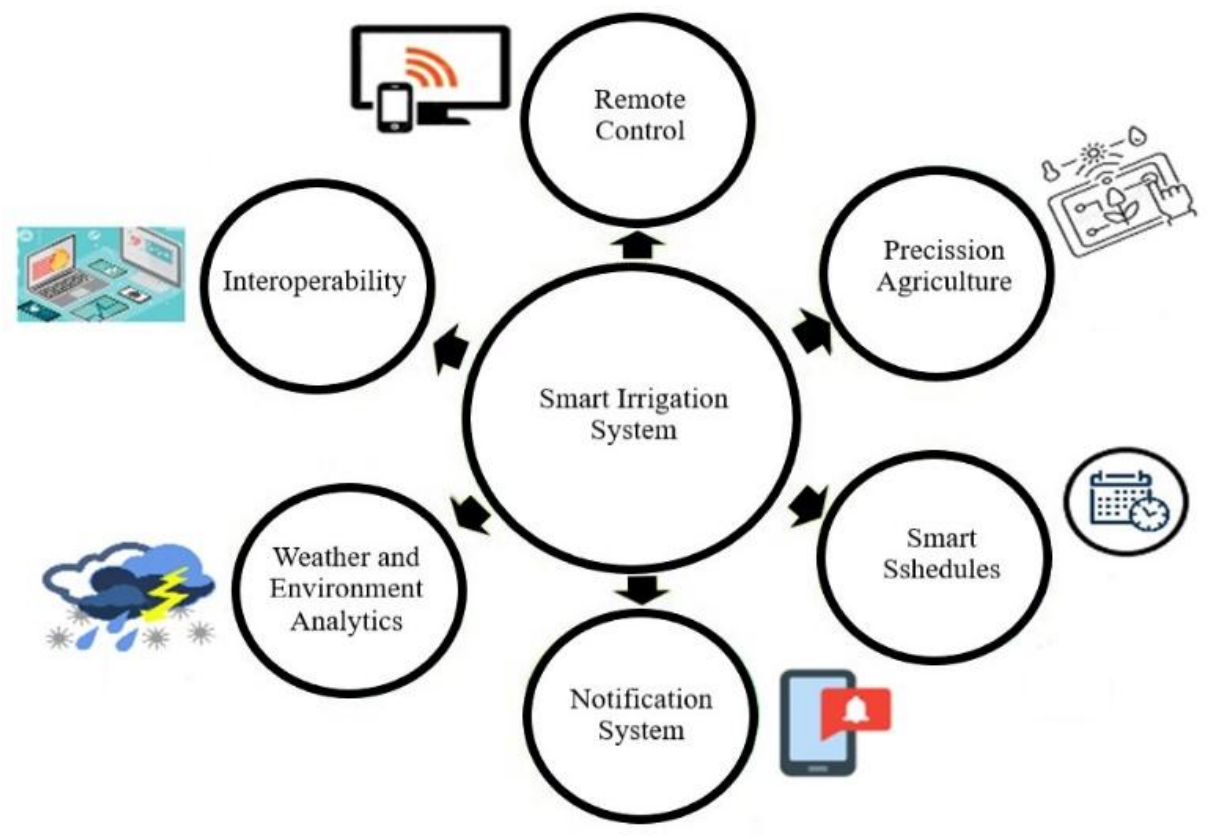

Figure 1. Functions of Smart Irrigation Systems

\section{RELATED WORKS}

There are several benefits in developing microcontroller-based circuits and incorporating new device technologies into agricultural applications.At present, labor-saving and water-saving technology could also be a key issue in irrigation. There are many existing irrigation systems are available within the market and lots of researchers performing on it. The system in [3], is used an Arduino and esp8266 module to provide automatic irrigation. However, these two can be replaced with a single NodeMCU esp8266 module which can reduce the system cost and complexity.

The author proposed a system in [4], that could be a PLC-based system wherever water management flow is controlled by PID controller.However, the system isn't cheap for poor farmers in their agricultural fields. An expensive fuzzy controller and fuzzy logic-based irrigation system developed for the agricultural plantation, which system response becomes slow [5,6,7].

System [8] is extremely complicated, during this system their software and information are created regionally thus it needs skilled farmers to monitor it.A bulky and expensive system [9], is used Zigbee WSN technologies for wireless communication between the controller and different end devices. This system is wireless however not IoT that the system cannot be controlled from a remote location.Now this paper aims to attain all the essential needs of farmers at a reasonable price for the poor farmers. we have a tendency to design the IoT-based smart Irrigation system using the ESP8266 microcontroller board and basic sensor with a controllable water pump. 


\section{Proposed Methodology}

The basic building blocks of an IoT System are Sensors, Processors and applications. The block diagram shown in Fig. 2 is the proposed model which shows the interconnection of these blocks. The sensors are interfaced with Microcontroller (here Node MCU), data from the sensor is displayed on the cloud. The cloud provides an access to the continuous data from sensors and accordingly helps farmer to take action to fulfill the requirements of the soil moisture level.

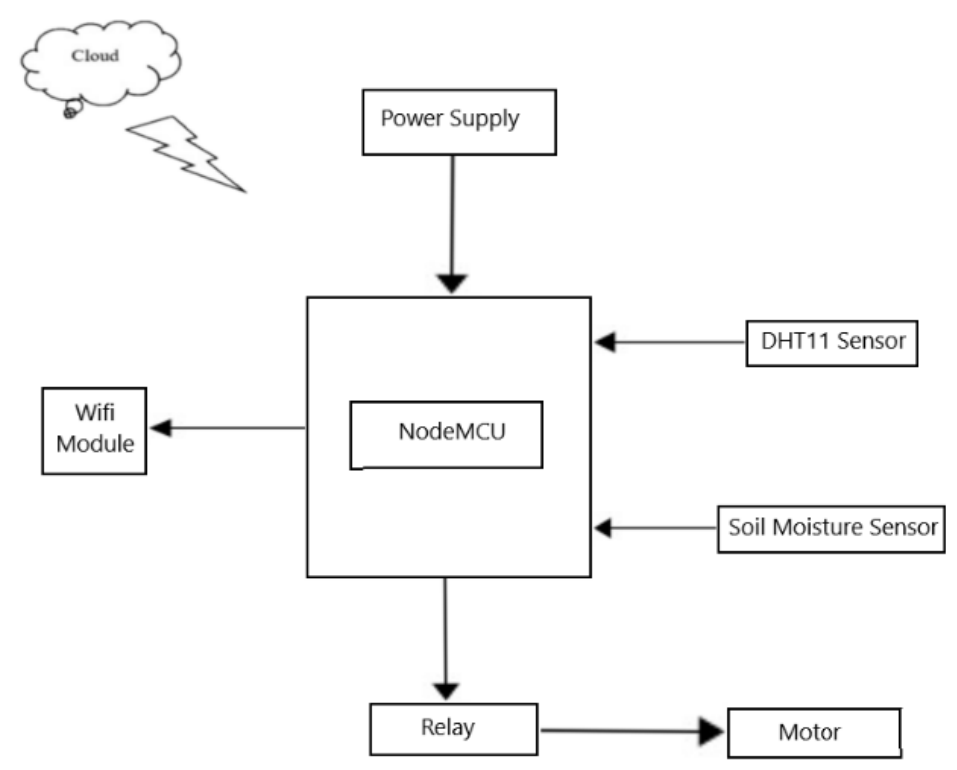

Figure 2. Block Diagram of Proposed Model of Smart Irrigation Systems

A well-designed web page is created using Hypertext Markup Language (HTML) shown in figure 3. HTML is the standard markup language that is familiar to build a web page and its content. Once the user puts his Thingspeak channel ID\& API key properly, the user get access to change the motor status by using the designed web page (shown in figure 3 ). To control the motor ON or OFF action, when user simply click on the "Motor ON" or "Motor OFF" button, the associated Thingspeak field (Relay Data) with this web page will go high (logic 1) or low (logic 0) respectively.

A working flowchart of proposed Smart Irrigation Systems is shown in Fig. 4. The Node MCU will continuously read the Thingspeak field (Relay Data). When Node MCU will sense that the field value goes high (logic 1), then it will energize the relay coil. As a result, relay will short the motor circuit and water will flow to irrigate the agricultural field with efficient manner. On the other hand, when Node MCU will sense that the field value goes low (logic 0 ), the reverse process will happen. 
International Journal of Ambient Systems and Applications (IJASA) Vol.09, No.1/2, June 2021

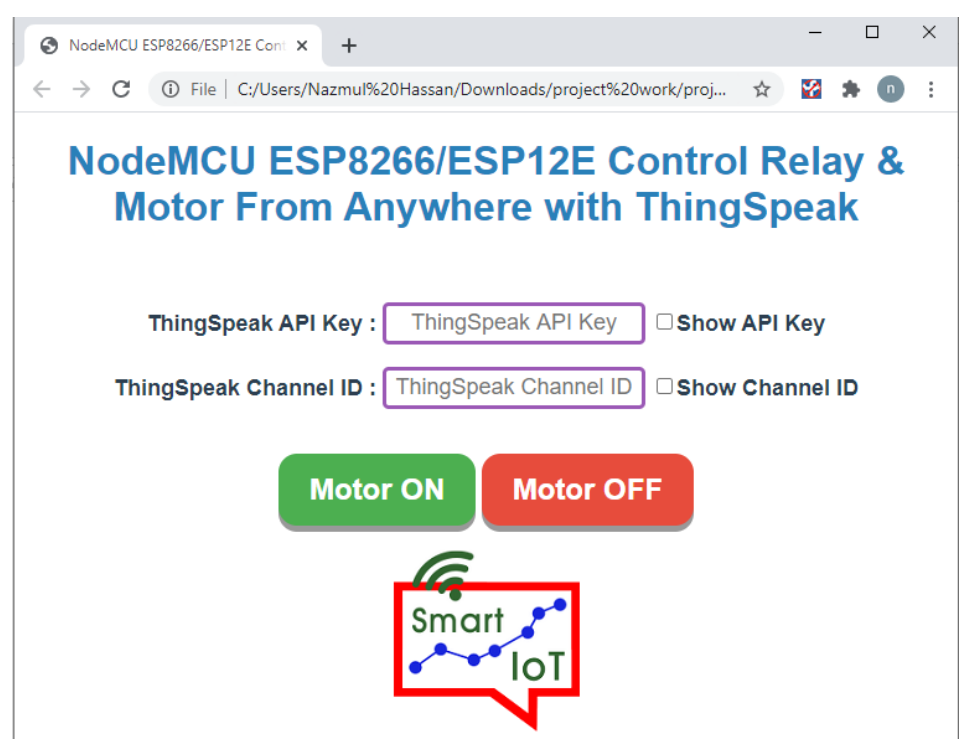

Figure 3. Designed web Page to control the motor

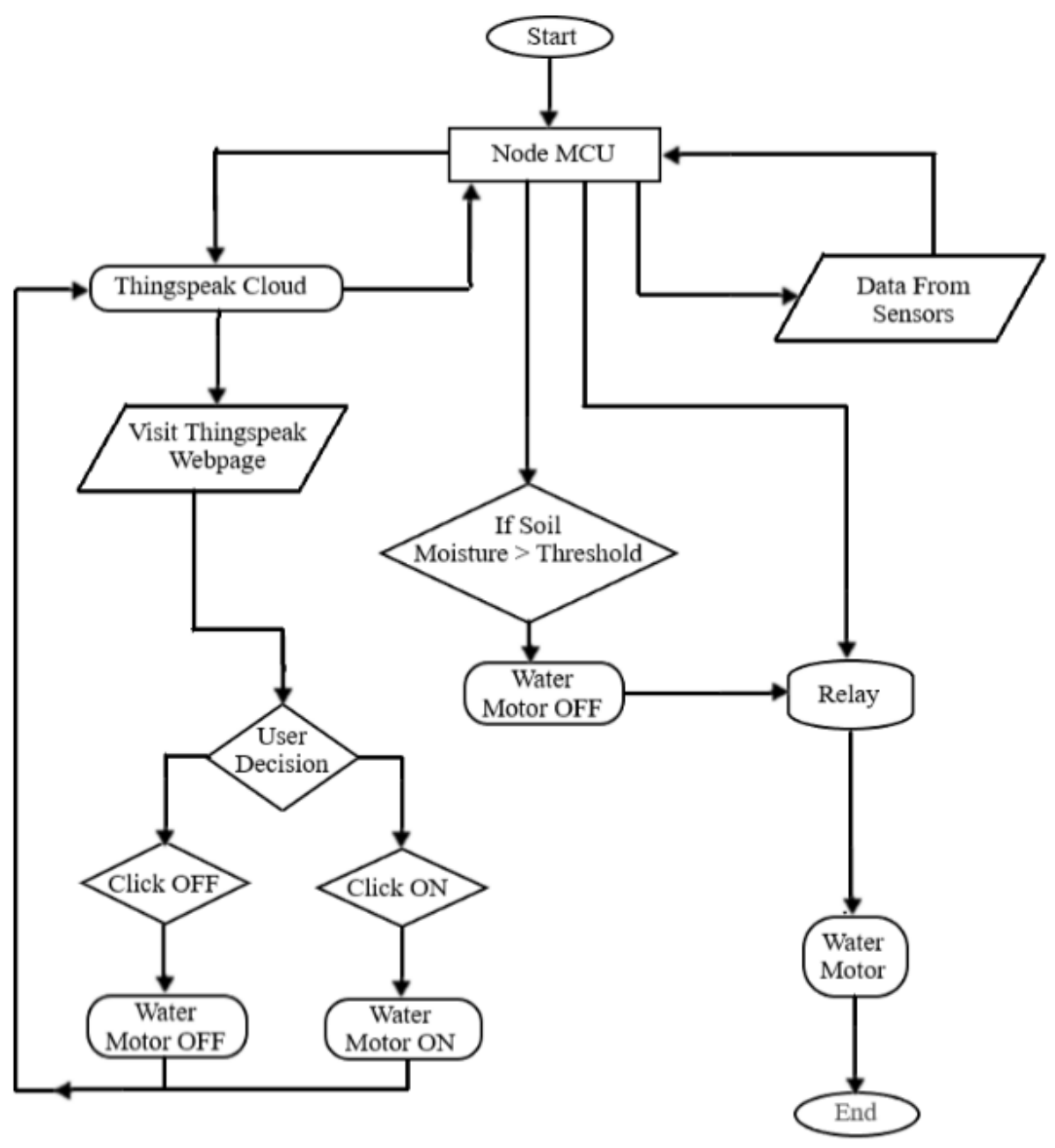

Figure 4. Flowchart of the Proposed Smart Irrigation Systems 
When the data of different sensors that are humidity, temperature and soil moisture is acquired, it is sent to the cloud.The user continuously monitoring these data. If the water content in the soil is less than the lower cut off value or greater than the threshold value then user will take his/her decision to ON or OFF the motor by analyzing the other parameters. The ON or OFF action of motor will be done by using a well-designed HTML page over cloud. Also, if the user forgets to off the water pump, the motor will stop automatically by the microcontroller, when the moisture level of soil will go above the upper threshold value.

\section{EXPERIMENTAL SETUP}

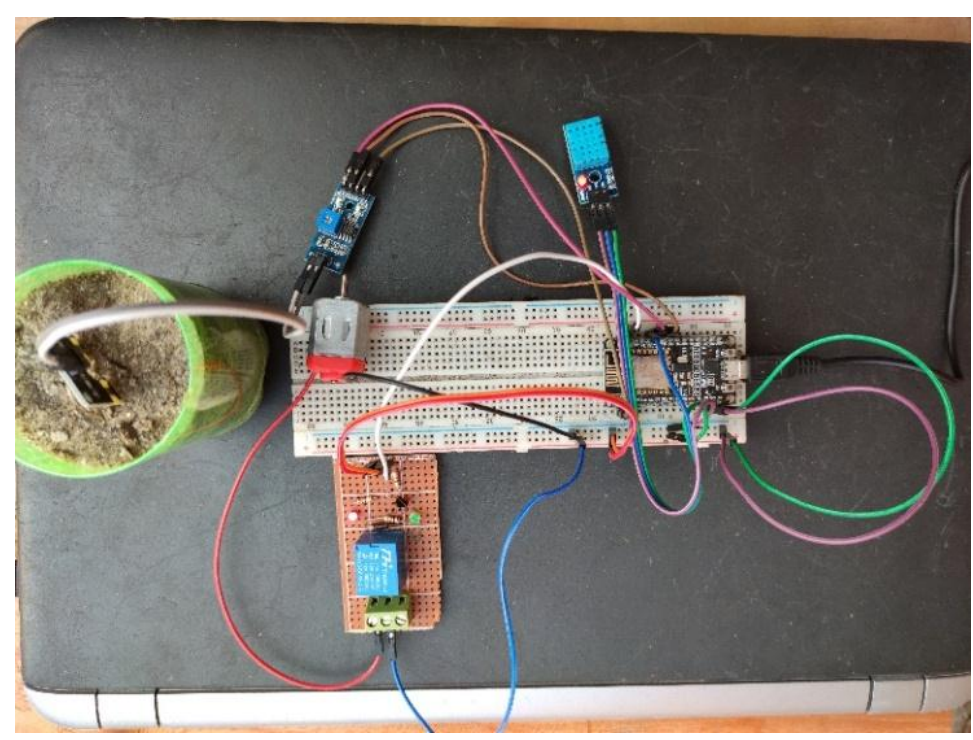

Figure 5. Practical Setup of Smart Irrigation System

Figure 5 shows the practical implementation of a smart irrigation system based on IoT. All the sensors are connected with NodeMCU to collect data from different fields. A relay module is used to control the motor status by node MCU.

\section{RESULTS AND DISCUSSION}

The actual readings of this technique are taken at a specific field for one day with a selected measure. Readings are taken within the daybreak, afternoon time, and already dark that are shown in Table 1, Table 2, and Table 3 severally. The figures shown below depict the sensing element readings of temperature, humidity, and soil wetness on the Cloud server.

\section{A. At Morning}

The variation of temperature with respect to time in the morning of a particular day is shown in Fig. 6(a). The data was monitored and recorded between 8:55 to 9:40 a.m. It is seen that the temperature was varied between 23 o to 240 C. Fig. 6(b) depicts the variation of humidity of the environment with time between 8:55 to 9:40 a.m of the same day in the morning. At 08:55 a.m. the value of the humidity was $83 \%$. Then it varied between $79 \%-81 \%$ with time and finally set at $80 \%$ at 09:40 a.m. The recorded soil moisture versus time graph of that day between 8:55 to 9:40 a.m is shown in Fig. 6(c). It is observed that the soil moisture value was varied over time in the morning. At 08:55 a.m. the value of soil moisture was 55\%, which was decreased to $46 \%$ at 09:45 a.m. 
International Journal of Ambient Systems and Applications (IJASA) Vol.09, No.1/2, June 2021

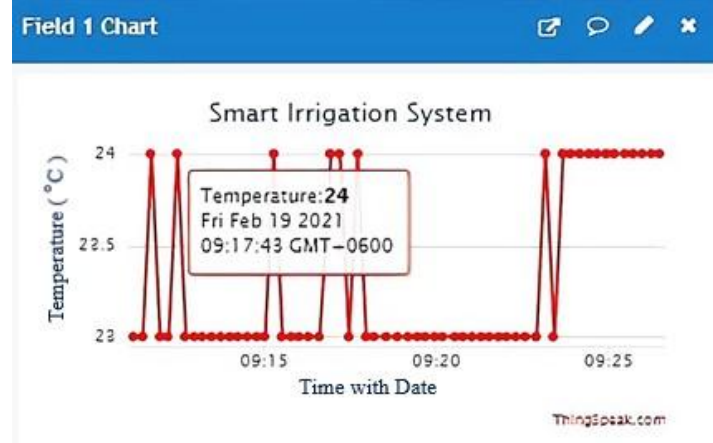

(a)
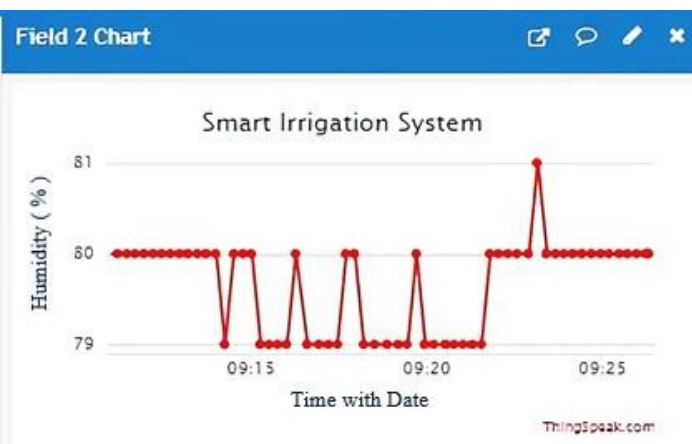

(b)

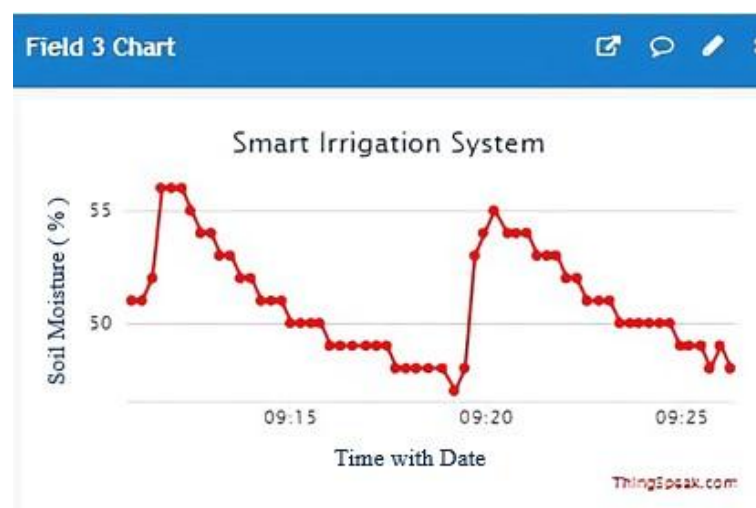

(c)

Figure 6. Recorded data in the morning (a) Temperature Vs Date/Time graph; (b) Humidity Vs Date/Time; (c) Soil Moisture Vs Date/Time

The status of the water pump between 8:55 to 9:40 a.m in the morning of that particular day is shown in Fig. 7. The value 0 means the water pump was in off state. The pump was in off condition throughout the observed time because the values of soil moisture were higher than the lower threshold (here $30 \%$ ) value of the wetness of the soil.

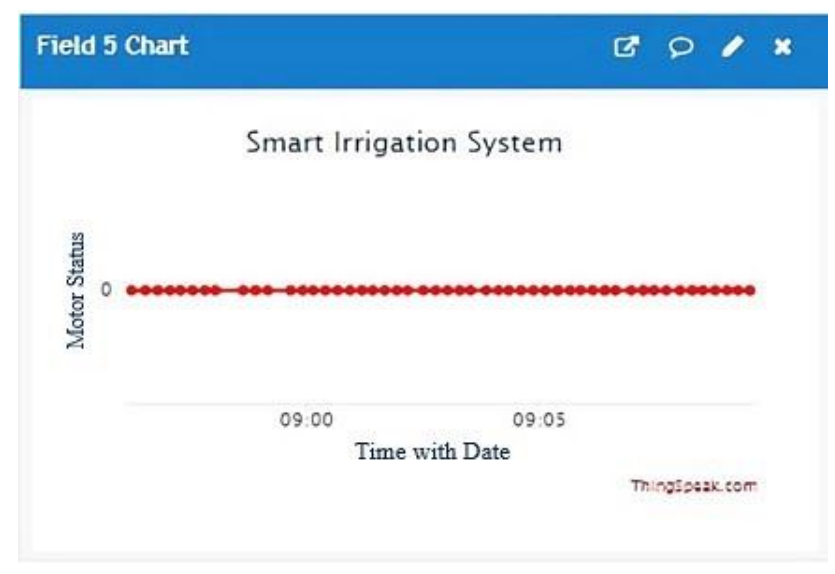

Figure 7. Graph of Motor Status in the morning 
International Journal of Ambient Systems and Applications (IJASA) Vol.09, No.1/2, June 2021

\section{B. At Afternoon}

The variation of temperature with respect to time in the afternoon of a particular day is shown in Fig. 8(a). The data was monitored and recorded between 14:45 to 15:25 p.m. It is seen that the temperature was varied between $24 \mathrm{o}$ to $25 \mathrm{o}$ C. Fig. 8(b) depicts the variation of humidity of the environment with time between 14:45 to 15:25 p.m of the same day in the afternoon. At 14:45 p.m. the value of the humidity was $68 \%$. Then it varied between $69 \%-77 \%$ with time and finally set at $77 \%$ at 15:25 p.m. The recorded soil moisture versus time graph of that day between 14:45 to 15:25 p.m is shown in Fig. 8(c). It is observed that the soil moisture value was varied over time in the afternoon. At 14:45 p.m. the value of soil moisture was 39\%, which was initially decreased with time and going below the lower threshold value of $30 \%$ at 15:00 pm. After that, it was starts to increase at 15:09 p.m. after the water pump was turned on and rapidly increased to $79 \%$.

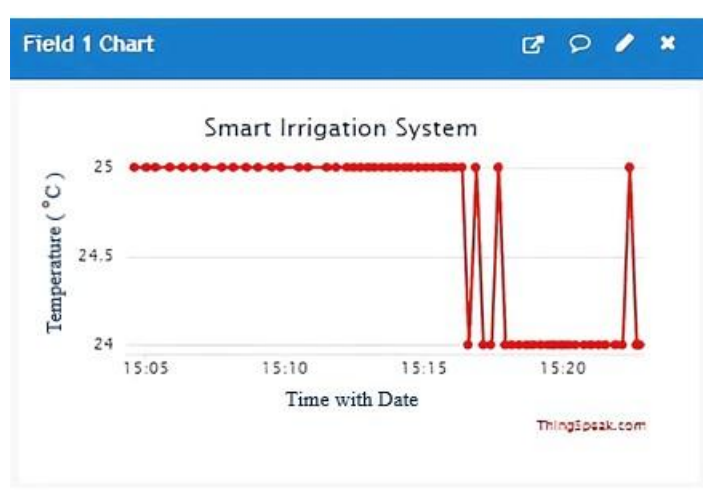

(a)

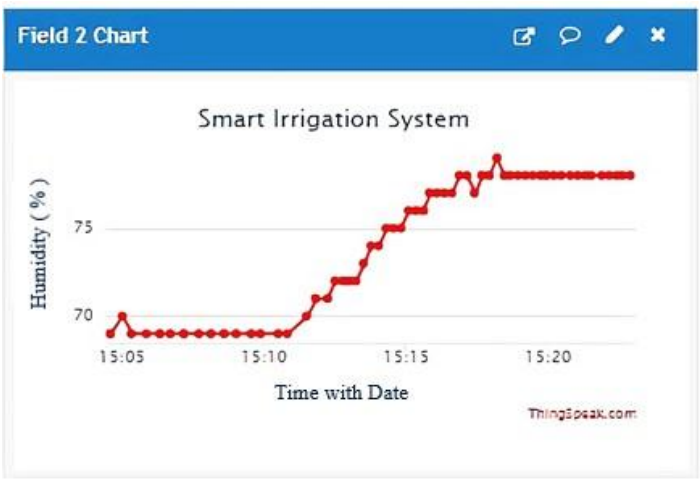

(b)

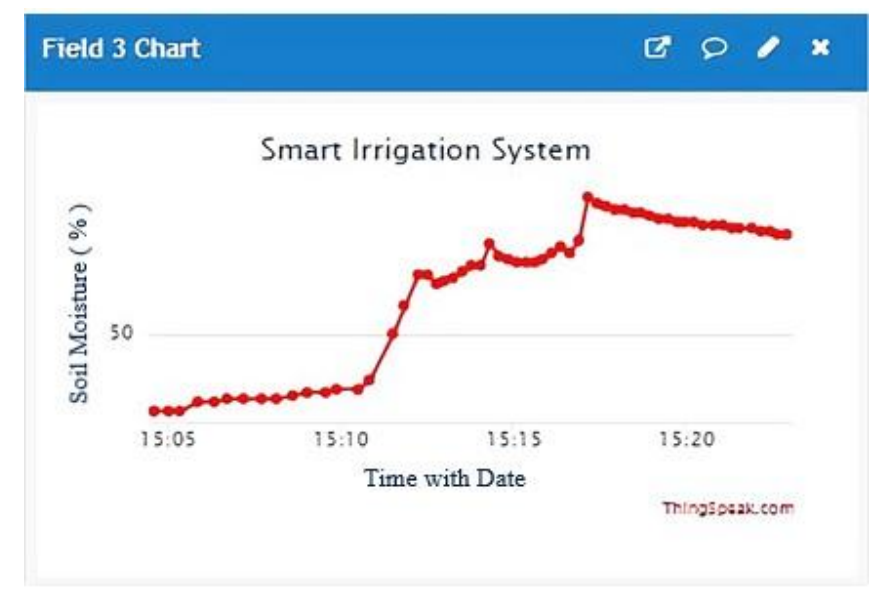

(c)

Figure 8. Recorded data in the afternoon (a) Temperature Vs Date/Time graph; (b) Humidity Vs Date/Time; (c) Soil Moisture Vs Date/Time 
International Journal of Ambient Systems and Applications (IJASA) Vol.09, No.1/2, June 2021

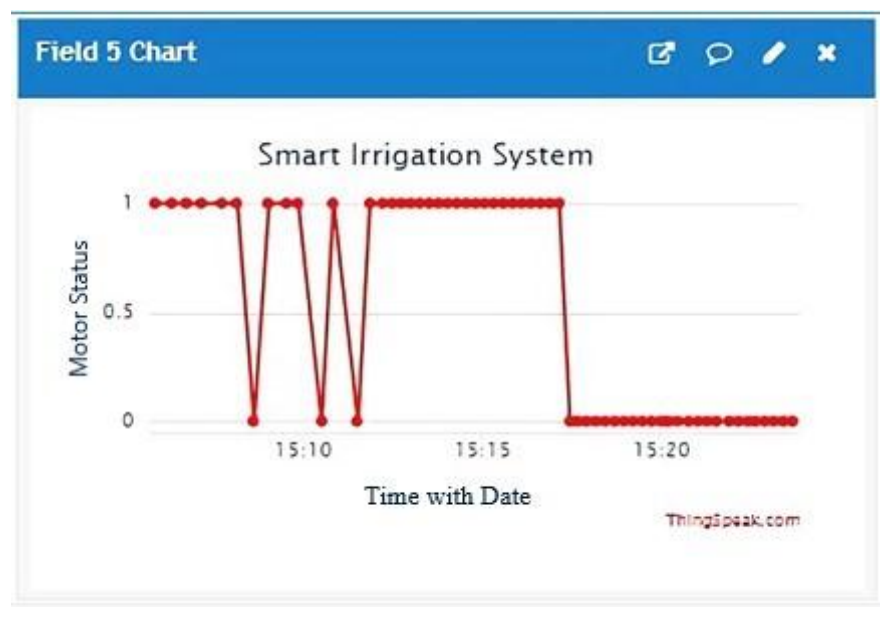

Figure 9. Graph of Motor Status in the afternoon

Figure 9 shows the motor status. The motor was turned on through the thinkspeak server at 15:09 and turned off automatically by the microcontroller at 15:18. The value of soil moisture was below the lower threshold (here 30\%) at 15:00. The motor was then turned on (when motor status 1) manually by the user using the designed HTML page at 15:09. But when the value of soil moisture crosses the upper threshold (here $85 \%$ ) value, the water pump was automatically turned off (when motor status 0) at 15:20 p.m.

\section{At Night}

The variation of temperature with respect to time in the night of a particular day is shown in Fig. 10(a). The data was monitored and recorded between $22: 15$ to $22: 45$ p.m. It is seen that the temperature was varied between $23 \mathrm{o}$ to $24 \mathrm{o}$ C. Fig. 10(b) depicts the variation of humidity of the environment with time between 22:15 to 22:45 p.m of the same day in the night. At 22:15 p.m. the value of the humidity was $81 \%$. Then it varied between $81 \%-82 \%$ with time and finally set at $82 \%$ at 22:45 p.m. The recorded soil moisture versus time graph of that day between 22:15 to 22:45 p.m is shown in Fig. 10(c). It is observed that the soil moisture value was varied over time in the night. At 22:45 p.m. the value of soil moisture was 76\% and it was varied between $75-82 \%$ during the observed time interval. As the moisture level of the soil at night was below $85 \%$ (Figure 10(c)), that is, below the higher threshold value, the motor condition was within the off state. the user was no need to turn on the motor.

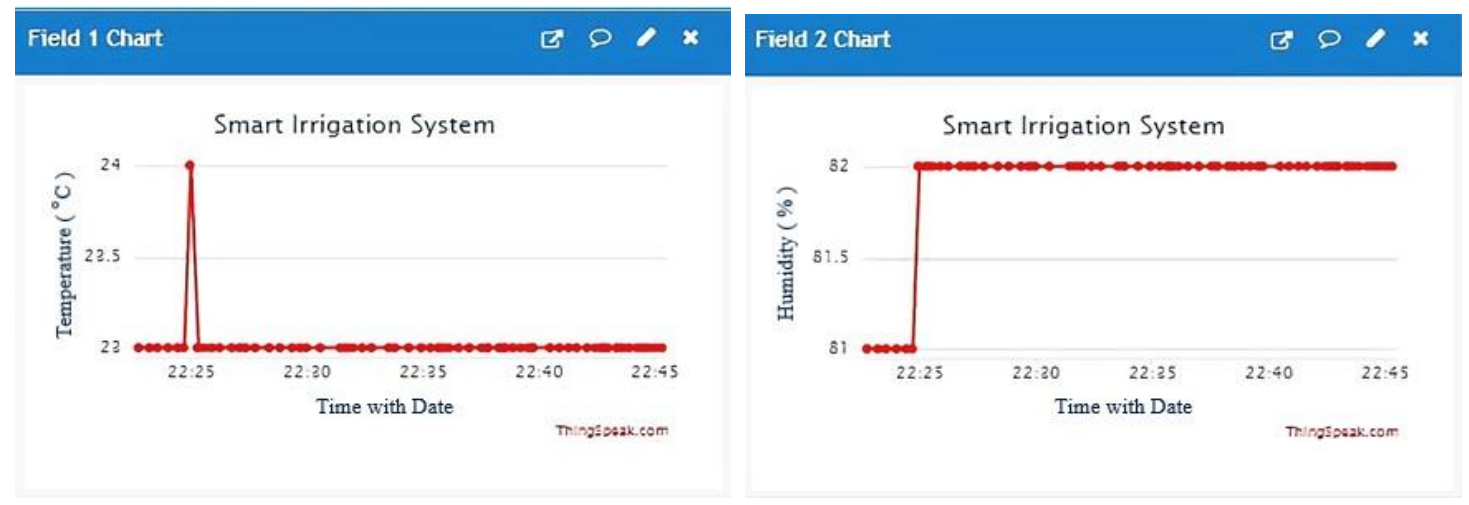

(a)

(b) 
International Journal of Ambient Systems and Applications (IJASA) Vol.09, No.1/2, June 2021



(c)

Figure 10. Recorded data in the night (a) Temperature Vs Date/Time graph; (b) Humidity Vs Date/Time; (c) Soil Moisture Vs Date/Time

Figure 9 shows the motor status. In this case, water pump was also in off state (when motor status is 0 ) condition during the time of observation, as the values of soil moisture were above the lower threshold (here $30 \%$ ) value.

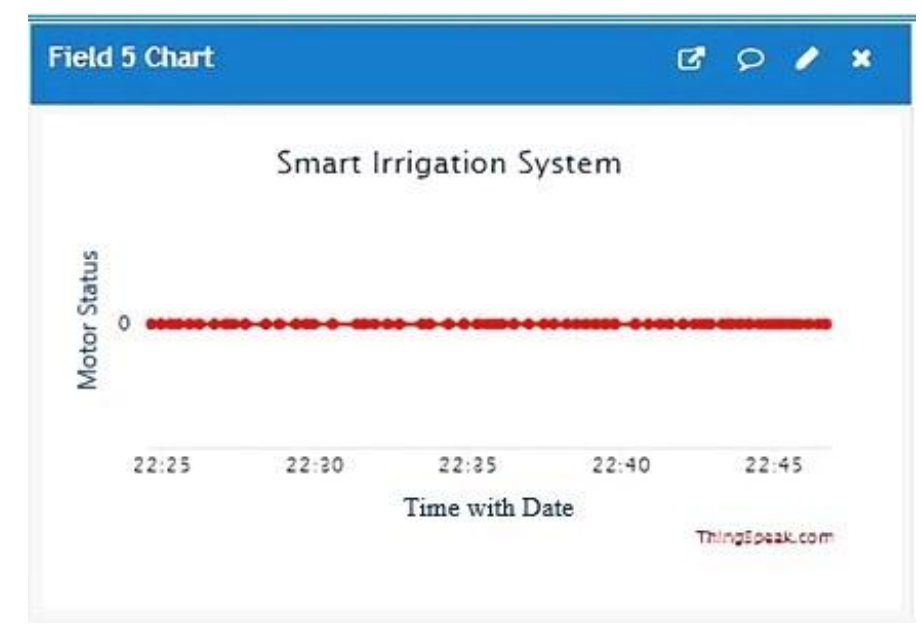

Figure 11. Graph of Motor Status in the night

\section{Conclusions}

In this paper, we have successfully developed a sensor based smart irrigation system with the capabilities of remote monitoring and controlling of water usage in the agriculture field using IoT. The system consists of a microcontroller (Node MCU), sensors (soil moisture, DHT11), and irrigation of a water pump with a decision-making system. Sensors are linked to a Wi-Fi module (Node MCU) and are interdependent to provide increased sensitivity to the irrigation system. The data obtained has been uploaded to the cloud (ThingSpeak) and presented in the form of graphs accessible via the website. A web page is used to control the water pump for irrigation purposes. This IoT based smart irrigation system uses minimum human efforts and permits the user to monitor and control the wet of the soil to the crop in an efficient and economic way. It can also improve irrigation ways, increase productivity, ensure effective uses of restricted resources, 
International Journal of Ambient Systems and Applications (IJASA) Vol.09, No.1/2, June 2021

decrease implementation and maintenance cost as compared to the available automatic irrigation system. So this system is very useful for poor farmers in their farming.

\section{REFERENCES}

[1] S. Marston, Z. Li, S. Bandyopadhyay, J. Zhang, and A. Ghalsasi, "Cloud computing - The business perspective,” Journal of Decision Support System.,Vol. 51, Issue 1, pp. 176-189, April 2011.

[2] Dr. J. Jegathesh Amalraj, S. Banumathi and J. Jereena John, “ IOT Sensors and Applications: A Survey”, International Journal of Scientific \& Technology Research, Volume 8, Issue 08, Pages: 998$1003,2019$.

[3] Yiming Zhou, Xianglong Yang, Liren Wang, Yibin Ying, "A wireless design of low-cost irrigation system using ZigBee technology", in proceedings of the International Conference on Network Security, Wireless Communications and Trusted Computing (NSWCTC ‘2009), pp. 572-575, April 2009.

[4] Hamza Benyezza, Mounir Bouhedda and Khaoula Djellout "Smart irrrigation system basedThinkspeak and Arduino," in proceeding of the IEEE International conference on applied smart systems (ICASS '2018), INSPEC Accession Number: 18490272, Nov. 2018.

[5] Wu-quan He, Ming-ke Cai, Yu-bao Wang and Xiao-jian Wang, "Automatic Water Supply Control System of Graded Constant Pressure by Variable Frequency Speed and Its Application to Pipeline Irrigation," in Proceedings of the IEEE 2010 Second WRI Global Congress on Intelligent Systems, INSPEC Accession Number: 11806217, Dec. 2010.

[6] Guifen Chen and Lisong Yue, "Research of Irrigation control system based on fuzzy neural network," in Proceedings of IEEE International Conference on Mechatronic Science, Electric Engineering and Computer (MEC), INSPEC Accession Number: 12327208, August, 2011.

[7] Ban Alomar, Azmi Alazzam "A Smart Irrigation System Using IoT and Fuzzy Logic Controller" in Proceedings of IEE Fifth HCT Infromation Technology Trends (ITT), NSPEC Accession Number: 18474254, Nov. 2018.

[8] Vaishali S, Suraj S, Vignesh G, Dhivya S and Udhayakumar S " Mobile Integrated Smart Irrigation Management and Monitoring System Using IOT" in Proceedings of IEEE International Conference on Communication and Signal Processing (ICCSP), INSPEC Accession Number: 17575192, April 2017.

[9] Fei Hu and Lei Shao, "Design of Remote Irrigation System in Farmland based on the cloud platform," in Proceedings of IEEE 29th Chinese Control and Decision Conference (CCDC), INSPEC Accession Number: 17041084, May 2017. 